\title{
The Linkage Mode of Training Students' Ability of Practice, Innovation and Entrepreneurship in Higher Education
}

\author{
Xiao-li Zhang ${ }^{1}$, Jun-qiang Zhao ${ }^{1}$, Lian-juan $\mathrm{He}^{2}$, Lan-zhi $\mathrm{He}^{2}$ \\ 1 School of Foreign Languages Lanzhou University of Technology, Gansu Province, China \\ 2 Academic Affairs Department Lanzhou University of Technology, Gansu Province, China
}

\begin{abstract}
The training of high quality talents with specialty in knowledge application is the need to adapt to economic and social development, while to improve quality of practical teaching is an important guarantee for cultivating applied high quality talents. Starting from the exploration of problems existing in the practical teaching of the current higher education and the situation of practical teaching in our school, this paper, engaged in the solid thinking of how to strengthen the practical teaching in higher education, examines the linkage mode of training students' ability of practice, innovation and entrepreneurship.
\end{abstract} mode

Index Terms - higher education; practical teaching; linkage

\section{Introduction}

To strengthen practical teaching, strengthen the training of college students' practical, innovative and entrepreneurial ability, is the important content of improving the quality of intellectual training. How to strengthen students' practical proficiency and enhance their employment ability is a profound significance for universities with specialty in science and technology.

Firstly, the paper explores the existing problems in practical teaching and the framework of linkage mode; then taking Lanzhou University of Technology as an example, some feasible qualifications are discussed; finally some proposals to reform the traditional teaching model, to change the educational ideas and to strengthen the practical teaching for the development of innovative thinking and entrepreneurship education are offered.

\section{The Background and Research Status at Home and Abroad}

On the afternoon of August 18, 2013, the premier of State Council, Li Keqiang, made a special trip to Lanzhou University for an in-depth understanding of the employment situation of college students with his expectation that the majority of students should be innovative talents, daring to do pioneering work to serve the society and create wealth. The Prime Minister stressed that "college students should not only be employed, but also be encouraged to start businesses". They should have the double pioneering spirit that is the innovation consciousness and the spirit of entrepreneurship. Time will not be waited and every minute will be seized for the cultivation of university students' practical ability, innovative ability and entrepreneurial ability.
At present, many countries like America, Japan, Germany, Switzerland, India and other countries with the wellknown colleges and universities have attached great importance to the cultivation of innovative talents with the strategic height and corresponding measures to promote the development of students' personality, cultivate and improve their innovative ability in practice, to achieve good results. In the curriculum, many research courses are offered in USA with groups as the class discussion; as well as an independent study course (mainly students' self-study course); with the special attention on the curriculum development and innovation. In the way of teaching, in addition to the use of role play, simulation, debate and case analysis and so on, the conventional way is also used. At the same time, through interaction between teachers and students in the teaching process the initiative and consciousness of students is fully mobilized to enhance their self-confidence, to develop their creative thinking ability. In practice, students are encouraged to participate in various community activities and social activities. Entrepreneurship Education is receiving great attention in some developed countries, such as Britain, France, Germany, USA, Japan, and Singapore. In talent training, the focus is on training students' research ability.

Domestically, the practice of practical education in the past, the cultivation of College Students' various abilities was often out of touch, being in an isolated state closed to each other, with each management department lacking effective information exchange, communication and cooperation so that a variety of waste of resources and the phenomenon of culture shortage is caused. Some domestic scholars have explored the training of students' practical, innovative and entrepreneurial ability from different perspectives. Dong Liang (2007) talked about how to strengthen the cultivation of students' innovation ability under the new situation. Gao Jingping (2012) studied the status of college students' innovation quality in China. He Xingbing (2012) described the effective ways to improve the innovation ability of university students. Li Zhike (2013) conducted the practice research and training of innovation ability of college students. But too much research has been classified as a theoretical description without linkage mechanism for the cultivation of practical ability, innovative ability and entrepreneurial ability. 


\section{The Existing Problems}

Since its official start in the year 2007, the National College Students' Innovation and Entrepreneurship Training Program has been carried out in the local 120 key universities with its most extensive coverage and the biggest impact as the project to ensure the undergraduate teaching quality and teaching reform.

At present, university students' innovative undertaking appears positive, with students' demand for the innovation and entrepreneurship training also growing with each passing day, colleges and universities being required to increase the innovation and pioneering efforts in various aspects to meet the needs of college students' comprehensive abilities and the needs for the development of students' social capacity, with the attention on cultivating students' innovative ability, but the innovation and entrepreneurship education is a systematic project, a new method of thinking needs to be explored. At the national level, the innovation and entrepreneurship training starts late, without the adequate policy propaganda to support the training of college students' creation and innovation. In the social aspect, the influence of college students' innovation and entrepreneurship training is not strong, with only a weak atmosphere of innovation and entrepreneurship to encourage the formation of innovation culture. At the school level, innovation and entrepreneurship training education teaching theory is not perfect, with only elective courses for the minority of students. Thus, the relationship among schools, enterprises and society needs to be improved. Since the achievement of innovation and entrepreneurship training has the characteristics of being invisible, delayed and so on, and great difficulty is also added to the education evaluation.

In a word, the traditional teaching mode has fettered students' innovative ability, with examination-oriented education hindering the cultivation of students' innovative ability, thus the students' autonomous learning awareness needs to be improved.

\section{A New Mode of Practical Teaching}

1) The talent training programs are to be improved and the time of practice teaching is to be ensured. In the talent training programs, the school shall clearly stipulate credits and class hours of the practice teaching link (experiment, practice, course thesis, graduation thesis (design) etc.), especially the experimental class proportion, once determined, should be conscientiously implemented, and shall not be arbitrarily changed, to formulate strict examination and approval process to ensure the teaching time of practice.

2) The content of practical teaching is to be carried out throughout "three classes" with the linkage model of practical teaching.

The first class: in addition to the experiment, practice, course design and course thesis are also included to ensure the comprehensive ability; professional practice including the graduation thesis, graduation design as well as other practical teaching links.
The second class: Students' Association, various types of training, research test, independent practice, academic competitions and activities of science and technology etc.

The third class: social practice, internship, cooperative education etc.

The content of practical teaching is carried out throughout the "three classes" to meet the need of the academic credit system. All credits got from activities such as social practice, independent practice training in foreign languages and computer for the required credits in the first class directly can extend to the second or the third process of practical teaching. Creative credits can be provided in the programs such as winning the competition in the newspaper or periodical publication of papers; or other related certificates; the students' participation in various activities including lectures and reports can be calculated in accordance with the time setting quality credit. The innovation credits, quality credits and skill credits, all these three credits can be used as elective credits in the second class, but also can replace the elective credits got from the first class, in order to realize the organic interaction of "the three classrooms" for the credits, thus the linkage of a practical teaching system can be formed in the circulation of three classrooms.

\section{Proposals to Deepen the Reform of Practical Teaching}

1) The law of cognition, education can be followed to break the habits of traditional practical teaching with its attachment to theoretical teaching. In the new system, the practical teaching is closely linked to and mutually independent from the theoretical teaching with the characteristics of open practical teaching system, to create a new mechanism of rich initiative, creative practical teaching model in an independent operation.

2) The students' innovative spirit and practical ability as the goal can be enhanced for the future social and economic development for the practical abilities of talents. The whole teaching content of the course practice can be strengthened in terms of the core professional practical ability, to adapt to the construction of economic and social development, to make the professional practical teaching plan more scientific, reasonable. Practical teaching scheme should be integrated with the theoretical practice, to improve practical teaching pertinence, to make sure that the practical teaching is carried out throughout the whole process of talent training for the integrity of teaching resources and a good situation in the whole society to support the practical teaching.

3) The application of modern information technology in teaching practice can be strengthened, gradually to improve the proportion of open designs, comprehensive researches and innovative experiments. Teachers should be encouraged to apply research results to practical teaching, thus promoting the improvement and renewal method of practical teaching. Students should be organized to participate in all kinds of scientific and technological innovative activities and the teachers' scientific research work, with the students' research ability and innovative ability being trained and improved. The 
practice of the teaching reform should be paid attention to in the research to support the development of experimental projects and teaching equipments.

4) The importance of experimental courses, practical teaching can be emphasized in guidance books, in the construction of teaching material and teaching planning, in the preparation unified into the construction and management of school materials, to ensure the quality of teaching materials. According to the dynamic characteristics of the development of disciplines, the content of teaching materials should be continuously improved for the preparation of the innovative teaching content. The aspect of excellent teaching material evaluation, teaching material construction should be inclined to the practical teaching.

5) The National College Students' Innovation and Entrepreneurship Project should be further increased to ensure better conditions for the undergraduates' participation in the activities of scientific research to organize the implementation of national and provincial College Students' innovative projects; The existing various extracurricular technological innovations and the practice of project resources can be integrated and optimized to increase the proportion of entrepreneurial practice, social practice and the development of other comprehensive skills to provide better conditions for the cultivation of students' different developments and compound talents; to guide the students to practice the curricular innovation activity. Graduation practice and teachers' scientific research can be closely connected together, to encourage students to select topics on their own, with their independent designs, independent researches as the main body of the innovative practice activity, to show students' practice and innovation results.

6) The cooperation between schools and enterprises should be actively promoted, thus the advantage of the industry, the establishment of teaching practice being stably displayed. Students' participation in scientific research, production and social practice can be supported to make the new training mechanism of talents combined with the exploration of universities and scientific research institutes, industries and enterprises.

\section{Conclusion}

Through the education system, teaching reform, social practice, psychological quality education, universities need to consciously strengthen the training of students' practical ability, innovation consciousness and creative ability, to meet the needs of social development with the linkage mode.

\section{References}

[1] Dong Liang. How to strengthen the cultivation of students' innovation ability under the new situation. Pioneering With Science \& Technology Monthly, 2007, (9).

[2] Gao Jingping. The status of college students' innovation quality in China. Journal of Taiyuan Vocational College, 2012, (10).

[3] He Xingbing. The effective ways to improve the innovation ability of university students. High education Forum, 2012, (4).

[4] Li Zhike. The practice research and training of innovation ability of college students. China Electric Power Education, 2013, (14). 